Bangladesh J. Bot. 44(2): 185-191, 2015 (June)

\title{
GENETIC DIVERGENCE OF AROMATIC RICE (ORYZA SATIVA L.)
}

\author{
Ratna Rani Majumder*, Ripon Kumar Roy ${ }^{1}$, MA Khaleque Mian ${ }^{2}$ \\ AND NASRIN AKTER IVY ${ }^{2}$ \\ Plant Breeding Division, Bangladesh Rice Research Institute, Gazipur-1701, Bangladesh
}

Key words: Genetic diversity, D² analysis, Cluster analysis, Rice (Oryza sativa L.)

\begin{abstract}
Thirty aromatic rice genotypes were studied to assess the nature and magnitude of genetic divergence among them for grain yield and yield contributing characters. Based on 23 characters the genotypes were grouped into 5 clusters. Inter-distances were higher than intra-cluster showing a wide range of genetic diversity among the genotypes of different groups. The highest level of inter-cluster distance (73.48) was found between cluster IV and V. The highest intra-cluster distance (3.364) was computed to cluster V and the lowest 1.851 was observed in cluster IV. Panicle length, days to initial flower opening, spikelet sterility, pollen fertility and harvest index had maximum contribution towards genetic divergence of 30 aromatic rice genotypes. Genotypes having these characters in the genetically distant cluster could, therefore, offer a significant scope for the development of high yielding variety through judicious selection.
\end{abstract}

\section{Introduction}

Rice is the staple food for one third of the world's population (Poehlman and Sleeper 1995). More than 90\% of the world's rice are produced and consumed in Asia (Virmani 1996). Bangladesh is the fourth largest producer of rice in the world with the annual production of 123.13 lac metric tons (MOA 2006). Compared to mid-60s rice production has been almost doubled during the last three decades. But there is no scope to increase rice area and some land should be released for other crops. Thus increasing of the rice production must come from exploitation of heterosis. Intra- and inter-cluster study permits to select the genetically diverse parents to obtain the desirable recombinant in the segregating generations upon crossing. Inclusion of more diverse parents is believed to increase the chances for obtaining stronger heterosis and gives broad spectrum of variability in segregating generations (Joshi and Dhawan 1966). Considering the scope and necessity the present investigation has been undertaken to estimate the nature and magnitude of genetic divergence and the characters contributing to genetic diversity of 30 aromatic rice genotypes.

\section{Materials and Methods}

The experiment containing 30 aromatic rice genotypes was carried out at the experimental farm of Bangabandhu Sheikh Mujibur Rahman Agricultural University, Salna, Gazipur during November 2007 to May 2008. The experiment was laid out in RCBD with three replications. Two rows of $5 \mathrm{~m}$, each constituted the experimental unit. Healthy seedlings of 37 days old were transplanted in separate strips with $25 \mathrm{~cm} \times 20 \mathrm{~cm}$ spacing in the experimental field. The land was prepared thoroughly with proper ploughing followed by laddering to attain a good puddled condition. Fertilizers @ 180-100-70-60 kg/ha urea, TSP, MP and gypsum were applied, respectively. All fertilizers except urea were applied at the final land preparation. Total amount of

*Author for correspondence: <rrmajumder@yahoo.com>. ${ }^{1}$ Biotechnology Division, Bangladesh Rice Research Institute, Gazipur-1701, Bangladesh. ${ }^{2}$ Department of Genetics and Plant Breeding, Bangabandhu Sheikh Mujibur Rahman Agricultural University, Gazipur-1706, Bangladesh. 
urea was applied in three installments at 15,30 and 50 days after transplanting recommended by BRRI (1999). Weeding and other intercultural operation was done as and when necessary. The agronomic data were collected from 10 hills of each genotype. The statistical analysis for various characters under investigation were done and the analysis of variance for each of the characters was performed by F test and mean values were separated by DMRT (Steel and Torrie 1960) using MSTATC program. Genetic diversity was worked out following principal component analysis (Rao 1964) and generalized distance $\left(\mathrm{D}^{2}\right)$ analysis (Mahalanobis 1936) extended by Rao (1952). Clustering of genotypes was done according to Tochers method (Rao 1952). Multivariate analysis viz. principal component analysis, principal coordinate analysis, cluster analysis were performed using GENSTAT 5.5 program.

\section{Results and Discussion}

Non-hierarchical clustering using covariance matrix among 30 aromatic rice genotypes were grouped into 5 clusters (Table 1). The clustering pattern obtained coincided with the apparent grouping patterns performed by Principal Component Analysis (PCA). So the results obtained through PCA were confirmed by non-hierarchical clustering.

Table 1. Distribution of $\mathbf{3 0}$ genotypes of aromatic rice in five clusters.

\begin{tabular}{ccl}
\hline Cluster & No. of members & Genotypes \\
\hline I & 7 & Kalijira 3, Kalijira 5, Kalijira 7, Kalijira 9, Badshabhog 3, Sakkorkhora, \\
& 2 & Maloti 1 \\
II & 15 & Kalijira finer, Kataribhog \\
III & & Kalijira 1, Kalijira 8, Kalijira 10, Kalijira 13, Dubsail, Badshabhog 10, \\
& & Uknimadhu, Premful, Radhunipagal 2, Doirgura, Kalijira 4, Chinigura, \\
& 4 & Agali, Khasa, Badshabhog 6 \\
IV & 2 & Kalijira 12, Sorukamini 1, Chinisakkor, Radhunipagal l \\
V & & Keora, Benaful \\
\hline
\end{tabular}

The distribution pattern indicated that the maximum number of genotypes (15) was included in cluster III followed by cluster I (7), cluster IV (4) and cluster II and V (2). The clustering pattern of the genotypes under the study did not follow their geographical distributions. Genotypes within the same cluster originated from different geographical regions. This indicates that although genetic diversity is generally associated with geographical diversity, the former is not necessarily directly related to geographic distribution rather they did not follow the same trend and factors other than geographical separation are also responsible for divergence which might be due to genetic drift, selection and continuous exchange of genetic materials among the countries of the world. Non corresponding genetic diversity and geographic distribution were also reported by Mannan et al. (1993), Sinha et al. (1991), De et al. (1988), Chaudhury et al. (1999), Masud et al. (2003) and Chandra et al. (2007).

Canonical variate (vector) analysis was performed to obtain inter-cluster distances (Mahalanobis's $\mathrm{D}^{2}$ values). The values of inter-cluster distances $\left(\mathrm{D}^{2}\right)$ are presented in Table 2 . The highest inter-cluster distance was observed between cluster IV and V (73.48) indicated that the genotypes belonging to cluster IV was far diverged from those of cluster V. The lowest intercluster distance was observed between clusters I and III (5.65) indicated that they were less diverse. The intra-cluster distances were low for all the clusters with the range of 1.851 in cluster IV and 3.364 in cluster $V$ which indicated homogenous nature of the genotypes within the clusters. 
The inter-cluster distances in all of the clusters were higher than the intra-cluster distances suggesting wider genetic diversity among the genotype of different groups. The results are in agreement with Rahman et al. (1997) and Singh et al. (1996). Basher et al. (2007) also reported

Table 2. Average intra- and inter-cluster distances $\left(D^{2}\right)$ for 30 genotypes of aromatic rice.

\begin{tabular}{llllll}
\hline Cluster & I & II & III & IV & V \\
\hline I & 2.090 & & & & \\
II & 7.24 & 2.742 & & & \\
III & 5.65 & 7.81 & 1.937 & & \\
IV & 13.04 & 20.21 & 14.79 & 1.851 & \\
V & 65.10 & 60.13 & 60.23 & 73.48 & 3.364 \\
\hline
\end{tabular}

Table 3. Cluster mean for 23 characters of 30 genotypes of aromatic rice.

\begin{tabular}{llllll}
\hline \multirow{2}{*}{ Characters } & Cluster & & & & \\
\cline { 2 - 6 } & I & II & III & IV & V \\
\hline Plant height $(\mathrm{cm})$ & 133.5 & 120.8 & 134.1 & 133.9 & 112.3 \\
Tiller no./hill & 22.7 & 26.2 & 23.9 & 22.6 & 23.5 \\
Panicles/hill & 18.3 & 23.5 & 20.3 & 18.8 & 16.5 \\
Panicle length $(\mathrm{cm})$ & 26.5 & 26.6 & 26.8 & 27.4 & 23.6 \\
Flag leaf area $\left(\mathrm{cm}^{2}\right)$ & 31.4 & 29.9 & 36.9 & 32 & 59.6 \\
Angle of opened floret $\left(^{\circ}\right)$ & 24.4 & 34.6 & 27.8 & 29.4 & 24.3 \\
Exerted stigma (\%) & 1.9 & 4.2 & 1.9 & 1.4 & 2.7 \\
Days to initial flower opening & 139.6 & 135 & 139 & 138 & 144 \\
Days to 50\% flower opening & 148.6 & 141 & 146.6 & 143.5 & 159 \\
No. of primary branching & 10.3 & 9.4 & 10.5 & 11.3 & 8.5 \\
No. of secondary branching & 27.9 & 30.3 & 34.4 & 43.3 & 15.8 \\
Grain no./panicle & 140.5 & 90.4 & 164.3 & 236.6 & 56.3 \\
Spikelet sterility $(\%)$ & 15.6 & 13.4 & 18.4 & 18 & 35.9 \\
Days to maturity & 179.6 & 179 & 179.7 & 177.3 & 181.5 \\
Stigma length $(\mu \mathrm{m})$ & 723.3 & 1248.9 & 912.3 & 519.4 & 1201 \\
Anther length $(\mu \mathrm{m})$ & 2413.8 & 2325.5 & 2080.6 & 1923.1 & 1133.1 \\
Anther breadth $(\mu \mathrm{m})$ & 468.1 & 393.3 & 442.5 & 437.4 & 374.2 \\
Pollen diameter $(\mu \mathrm{m})$ & 40 & 45.5 & 40.8 & 40.2 & 28.1 \\
Pollen fertility $(\%)$ & 66.5 & 75.1 & 74 & 56.3 & 39.5 \\
1000 seed weight(g) & 18.1 & 14.9 & 14.4 & 11.9 & 25 \\
Grain yield/hill $(\mathrm{g})$ & 30.2 & 28.6 & 31.3 & 38 & 13.2 \\
Harvest index & 0.1 & 0.1 & 0.1 & 0.1 & 0.1 \\
Out crossing rate $(\%)$ & 84.4 & 87.1 & 77.5 & 81.2 & 64.3 \\
\hline
\end{tabular}

that inter-cluster distances were larger than intra-cluster distances in a multivariate analysis in rice. Genotypes belonging to the distant clusters could be used in hybridization program for obtaining a wide spectrum of variation among the segregates (Mokate et al. 1998). It is more beneficial if crossing might be carried out between genotypes belonging to different groups if their genetic distances $\left(\mathrm{D}^{2}\right)$ are greater than 12.5 (Wei et al. 1994). In the present study, the inter cluster distances between cluster $\mathrm{V}$ and other clusters ranged from 60.13 to 73.48 suggesting that crossing 
of genotypes belonging cluster $\mathrm{V}$ with desirable genotypes of other clusters would express heterotic effect.

Table 4. Latent vectors for 23 principal component characters of 30 genotypes of aromatic rice.

\begin{tabular}{lcc}
\hline Characters & Vector 1 & Vector 2 \\
\hline Plant height $(\mathrm{cm})$ & -1.0022 & 0.1960 \\
Tiller no./hill & -1.4674 & 0.4704 \\
Panicles/hill & 1.2907 & -0.5149 \\
Panicle length $(\mathrm{cm})$ & 2.1934 & 0.2754 \\
Flag leaf area $\left(\mathrm{cm}^{2}\right)$ & 0.7998 & -0.0259 \\
Angle of opened floret $\left({ }^{\circ}\right)$ & -0.5465 & 0.0366 \\
Exerted stigma $(\%)$ & 1.1097 & -0.2524 \\
Days to initial flower opening & 0.8427 & 0.1816 \\
Days to 50\% flower opening & 0.1026 & -0.1524 \\
No. of primary branching & 1.7399 & -0.2480 \\
No. of secondary branching & -1.7125 & 0.2664 \\
Grain no./panicle & 0.1213 & -0.0279 \\
Spikelet sterility $(\%)$ & 0.1609 & 0.0800 \\
Days to maturity & 0.7014 & -0.4107 \\
Stigma length $(\mu \mathrm{m})$ & 0.0180 & -0.0086 \\
Anther length $(\mu \mathrm{m})$ & -0.0165 & -0.0087 \\
Anther breadth $(\mu \mathrm{m})$ & 0.0094 & -0.0044 \\
Pollen diameter $(\mu \mathrm{m})$ & 0.5222 & -0.2291 \\
Pollen fertility $(\%)$ & 0.0076 & 0.0112 \\
1000 seed weight $(\mathrm{g})$ & 0.0369 & -0.2338 \\
Grain yield/hill $(\mathrm{g})$ & 0.4947 & -0.1406 \\
Harvest index & 12.1951 & 12.2354 \\
Out crossing rate $(\%)$ & 0.0182 & -0.0149 \\
\hline & &
\end{tabular}

Among 23 characters, cluster II stood first for 8 characters viz. tiller no./hill, panicles/hill, angle of opened floret $\left({ }^{\circ}\right)$, exerted stigma $(\%)$, stigma length $(\mu \mathrm{m})$, pollen diameter $(\mu \mathrm{m})$, pollen fertility (\%) and out crossing rate (\%) considering mean values (Table 3). So the genotypes of this cluster are good as parents for improving out crossing rate. The highest cluster mean value was achieved for plant height $(\mathrm{cm})$ in cluster III. Such result indicated that genotypes of these clusters were not as good as parental selection for further improvement. Among cluster V highest cluster mean value was achieved for six characters viz. flag leaf area $\left(\mathrm{cm}^{2}\right)$, days to initial flower opening, days to $50 \%$ flower opening, spikelet sterility (\%), days to maturity and 1000 seed weight (g) which have negative role to yield and its components. Thus genotypes of this cluster may not be good as parents for improving yield and yield components except 1000 grain weight. The highest cluster mean value was achieved for only two characters viz. anther length and anther breadth in cluster I. The entire five clusters showed highest cluster mean for harvest index (0.1). Highest cluster mean value was observed for panicle length $(\mathrm{cm})$, no. of primary branching, no. of secondary branching, grain no./panicle and grain yield/hill in cluster IV. So the genotypes of this cluster are good as parents for improving yield and yield components. 
Contribution of characters towards divergence obtained from canonical variate analysis is presented in Table 4. The value of Vectors I and II revealed that both vectors had positive values for panicle length, days to initial flower opening, spikelet sterility, pollen fertility and harvest index indicating the highest contribution of these traits towards the divergence among 30 genotypes of aromatic rice. Kumari and Rangasamy (1997) concluded that grain yield per plant made the largest contribution to total divergence. Bidhan et al. (2002) found that days to $50 \%$ flowering, grain length and grain yield per plant were major yield contributing characters to rice genetic diversity.

The cluster pattern of $\mathrm{D}^{2}$ analysis through non-hierarchial clustering has taken care of simultaneous variation in all the characters under study. However, the distribution of genotypes in different clusters of the $\mathrm{D}^{2}$ analysis has followed more or less similar trend of the principal component scores 1 and 2 of the principal component analysis. $\mathrm{D}^{2}$ analysis and principal component analysis were found to be alternative methods in giving information regarding clustering pattern of genotypes. Neverthless, the canonical vector analysis (CVA) provides information regarding the contribution of characters towards divergence of aromatic rice genotypes.

A two dimensional scatter diagram $\left(Z_{1}-Z_{2}\right)$ was constructed using component $\mathrm{I}$ as $\mathrm{X}$ axis and component II as $\mathrm{Y}$ axis, reflecting the relative position (Fig. 1). As per scatter diagram, the genotypes were distributed into 5 clusters. The cluster II and cluster V contained lowest number of genotypes and cluster III contained highest number of genotypes.

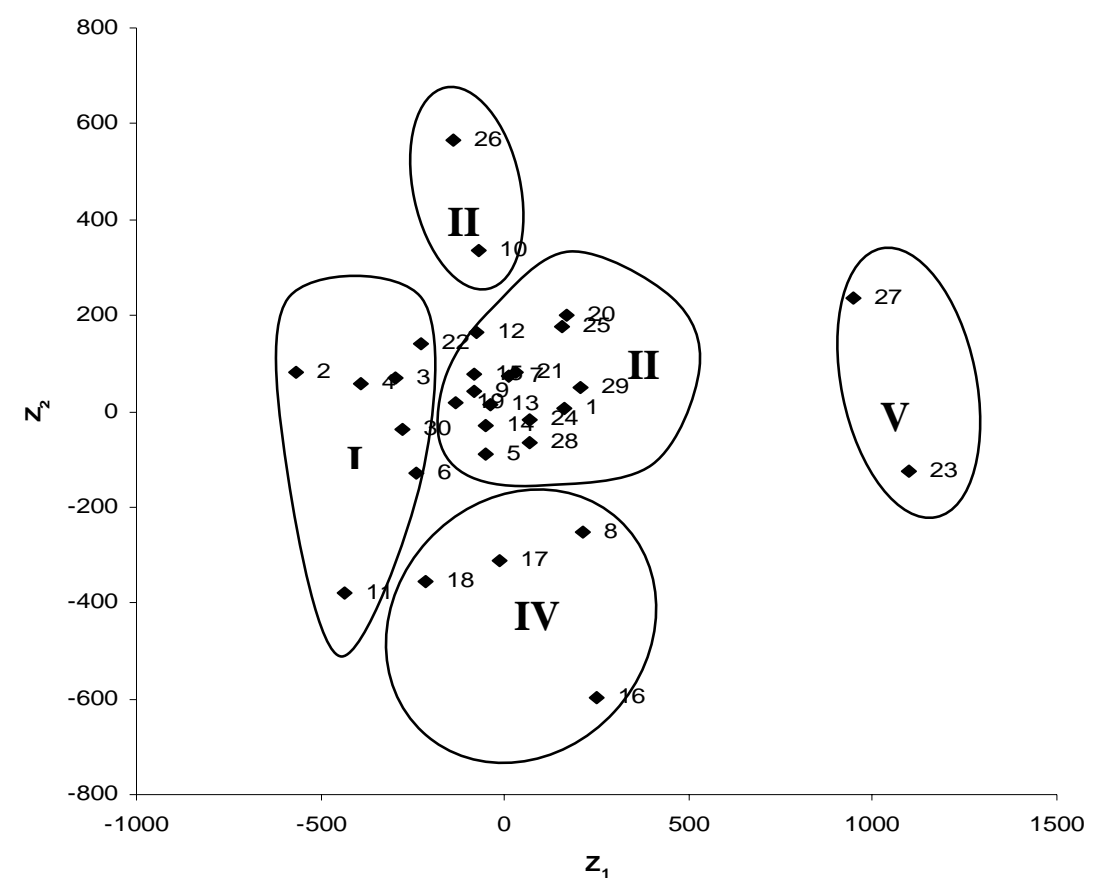

Fig. 1. Scatter diagram of 30 genotypes of aromatic rice based on their principal component scores superimposed with clusters.

Genotypes are to be selected on the basis of special objectives and no common criteria can be considered for selection of genotypes. Buu and Tuan (1989) suggested involving diverged 
genotypes in the hybridization program for getting transgressive segregants in rice. Considering magnitude of genetic distance, magnitude of cluster means of different characters, genotypes from cluster II could be selected for tiller no./hill, panicles/hill, angle of opened floret $\left({ }^{\circ}\right)$, exerted stigma (\%), stigma length $(\mu \mathrm{m})$, pollen diameter $(\mu \mathrm{m})$, pollen fertility $(\%)$, harvest index and out crossing rate (\%). Genotypes under cluster I could be selected for anther length, anther breadth and harvest index. The cluster II comprised of the genotype Kalijira finer and Kataribhog. Genotypes under cluster IV could be selected for panicle length, no. of primary branching, no. of secondary branching, grain no./panicle, grain yield/hill and harvest index. Genotypes under cluster $\mathrm{V}$ could be selected for flag leaf area, days to initial flower opening, days to $50 \%$ flower opening, spikelet sterility, 1000 seed weight and harvest index. Cluster III should be considered for harvest index only. Hybridization between the genotypes of cluster IV and cluster V will manifest maximum heterosis and create wide genetic variability due to highest inter cluster distance (73.48). Considering cluster distance and cluster mean, the genotype Kalijira 9, Kalijira 3 from cluster I, genotype Kataribhog from cluster II, genotype Badshabhog 10, Premful, Radhunipagal 2 and Kalijira 4 from cluster III, genotype Radhunipaga I from cluster IV and Keora from cluster V might be selected as a suitable parent for future hybridization program.

\section{References}

BRRI 1999. Time and requirement of topdressing of urea according to season and variety. Adhunik Dhaner Chash, Bangladesh Rice Res. Inst. pp. 28, Bangladesh.

Basher MK, Mian MAK, Nasiruddin M, Nur-E-Elahi, Julfiquar AW and Rasul MG 2007. Genetic divergence based on morphophysiological characters of some maintainer and restorer lines of rice (Oryza sativa L.). In: Proc. of the $7^{\text {th }}$ Biennial Conference of Plant Breeding and Genetics Society of Bangladesh held on May 26, 2007 at Bangladesh Rice Research Institute, Gazipur. pp. 72.

Bidhan R, Basu AK, Manda AB and Roy B 2002. Genetic diversity in rice (Oryza sativa L.) Genotypes under humid tropic of Andaman based on grain yield and seed characters. Ind. J. Agril. Sci. 72(2): 84-87.

Buu BC and Tuan TM 1989. Genetic diversity in rice (Oryza sativa L.). Int. Rice Res. Newsl. 14:6.

Chandra RS, Pradhan K, Singh S, Bose LK and Singh ON 2007. Multivariate analysis in upland rice genotypes. World J. Agric. Sci. 3(3):295-300.

Chaudhury DA, Hamid A, Bhowmik A, Mian GU and Islam MS 1999. Genetic divergence in indigenous rice (Oryza sativa L.) varieties of Bangladesh. Bangladesh J. Pl. Breed. Genet. 12(1\&2): 33-36.

De RN, Setharam R, Sinha MK and Banarjee SP 1988. Genetic divergence in rice. Ind. J. Genet. 48: 189-194.

Joshi AB and Dhawan NL 1966. Genetic improvement of yield with special reference to self fertilizing crops. Ind. J. Genet. Pl. Breed. 26A: 101-113.

Kumari RU and Rangasamy P 1997. Studies on genetic diversity in international early rice genotypes. Ann. Agril. Res. 18(1): 29-33.

Mahalanobis PC 1936. On the generalized distance in statistics. Proceedings of the National Academy of Sciences of India. 2:49-55.

Mannan MA, Ahmed MS, Rashid MM, Bhuiyan MKR and Gomes R 1993. Genetic diversity of Colocasia esculenta L. Ind. J. Root Crops 19(2): 95-99.

Masud MAT, Hossain MA, Saha SR, Muhammad A and Hossain SMM 2003. Genetic divergence in ridge gourd (Luffa acutangula L.). Bangladesh J. Pl. Breed. Genet. 16(2): 17-22.

MOA 2006. Handbook of agricultural statistics. MOA (Ministry of Agriculture). Government of the People’s Republic of Bangladesh. pp. 27.

Mokate AS, Mehetre SS, Bendake VW and Birari SP 1998. Genetic divergence in rice. Adv. Sci. 11(2): 189192.

Poehlman JM and Sleeper DA 1995. Breeding Field Crops. Panima Publishing Corporation. New Delh, India. pp. 278. 
Rahman M, Acharya B, Shukla SN and Pande K 1997. Genetic divergence in lowland rice germplasm. Oryza 34(3): 209-212.

Rao CR 1952. Advanced Statistical Method in Biometric Research. John Wiley and Sons, New York. pp. 390.

Rao CR1964. The use and interception of principal component analysis in applied research. Sankhya A. 22: 317-318.

Singh AK, Singh SB and Singh SM 1996. Genetic divergence in scented and fine genotypes of rice (Oryza sativa L.). Ann. Agril. Res. 17(2): 163-166.

Sinha PK, Chauhan VS, Prasad K and Chauhan JS 1991. Genetic divergence in indigenous upland rice varieties. Ind. J. Genet. 51(1): 47-5.

Steel RCD and Torrie JH 1960. Principles and Procedures of Statistics. McGraw Hill Book Co. Inc., New York. pp. 107-109.

Virmani SS 1996. Hybrid rice. Adv. Agron. 57: 379.

Wei WX, Zhang H, Lu FU and Wei SL 1994. Principal component analysis and genetic distance estimation and their application in sesame breeding programme. Acta Agriculturae Boreali Sinica 9(3): 29-33.

(Manuscript received on 9 April, 2014; revised on 10 September, 2014) 